УДК 616.314.18-002.4-031.81-085

DOI: $10.26435 /$ UC.V0I1(34).502

\author{
И.В. Бугорков, Е.В. Бухтиярова, И.А. Бугоркова
}

ГОО ВПО «Донецкий национальный медицинский университет имени М. Горького», Донецк

\title{
ОЦЕНКА ЭФФЕКТИВНОСТИ ПРИМЕНЕНИЯ ПРЕПАРАТА «МЕКСИДОЛ» В КОМПЛЕКСНОМ ЛЕЧЕНИИ БОЛЬНЫХ ГЕНЕРАЛИЗОВАННЫМИ ЗАБОЛЕВАНИЯМИ ТКАНЕЙ ПАРОДОНТА
}

Исследования, которые проводились в последние годы, наглядно продемонстрировали, что на фоне различных системных заболеваний в патогенезе заболеваний тканей пародонта значительное место занимает воспалительнодеструктивный процесс.

Сахарный диабет без преувеличения одно из самых распространенных заболеваний среди людей работоспособного возраста. По данным BO3 и международной федерации диабета (IDF), в настоящее время число страдающих этой болезнью в мире составляет 285 миллионов человек.

По прогнозам IDF, через 15 лет количество больных с сахарным диабетом, может увеличится на 150 миллионов. Самые высокие показатели заболеваемости диабетом отмечены в США, Россия - четвертая в этом списке [1].

Сахарный диабет различают инсулинозависимый (СД-1) и инсулиннезависимый (СД-2). В основном к данному заболеванию, подвержены пациенты с генетической предрасположенностью и пожилые люди, у данного контингента больных инсулин в организме вырабатывается в недостаточном количестве [2].

Болезнь провоцирует сбой в углеводном обмене, который обусловлен разрушением $\beta$-клеток в поджелудочной железе. В последствии такой сбой приводит к неспособности производить инсулин и за счет этого происходит ответная реакция организма на раздражающие и поддерживающие факторы, приводящие к повышению титра патогенной микрофлоры, которая аккумулируется на поверхности зубов и зубо-десневых карманах [2, 3].

Ранее проведенные исследования наглядно продемонстрировали, что воспалительнодеструктивные процессы тканей пародонта усиливается на фоне сахарного диабета, который влияет на общую резистентность организма [4, 5].
Сахарный диабет является многофакторным заболеванием и является составной частью метаболического синдрома. Существуют различные теории возникновения сахарного диабета, но одной из наиболее популярных последних теорий является теория предложенная G. Eisenbarth [5].

На фоне сахарного диабета происходит изменение индексных показателей тканей пародонта, которые приводят к нарушениям энергетических процессов в эпителиальных клетках, к изменениям метаболизма и нарушением на клеточном уровне барьерной функции, которая предрасполагает к тканевой гипоксии, которая в последствии приводит, к развитию хронического воспалительно-деструктивного процесса $[6,7]$.

Под воздействием микробного фактора отмечается окислительный стресс, который приводит к альтерации тканей пародонта. Распространенность и тяжесть заболевания в тканях пародонта находится в прямой зависимости от степени сахарного диабета. Происходящие при этом патоморфологические и патогистохимические изменения в тканях пародонта, инициируют разнообразие клинической картины заболевания, и определяет характер течения. Патогенная микрофлора в пародонтальном кармане вызывает комплекс микроциркуляторных, гематологических, иммунологических и соединительно-тканных реакций на повреждение удерживающего аппарата зуба $[8,9]$.

Известно, что бактериальный фактор ведет к повреждению структуры тканей, нарушению процессов дыхания, повышению проницаемости капиллярной стенки, формированию отеков, создавая благоприятные условия для агрессии микрофлоры [5, 7, 2].

() И.В. Бугорков, Е.В. Бухтиярова, И.А. Бугоркова, 2020 (c) Университетская Клиника, 2020 
В связи с этим очевидна актуальность поиска новых подходов подборе и использовании медикаментозных препаратов, которые обладали антиоксидантным, антигипоксантным и мембранопротекторными свойствами и действовали как барьер, придавая тканям пародонта устойчивость к повреждающим факторам.

Целью данного исследования является оценка эффективности препарата «Мексидол ${ }^{\circledR}$ и Мексидол ${ }^{\circledR}$ форте 250» (ООО Векторфарм, Россия) в комплексном лечении генерализованного пародонтита I-II степени тяжести, при лечении больных у которых имеется сахарный диабет 2-го типа.

\section{МАТЕРИАЛ И МЕТОДЫ}

Клинические обследования проведены у 46-и пациентов, которые одновременно (в период 2019-2020 гг.) находились на диспансерном учете в Университетской клинике на кафедре общей стоматологии ФИПО ДонНМУ им. М. Горького по поводу генерализованного пародонтита I-II степени тяжести, ассоциированного сахарным диабетом 2-типа и у врача-эндокринолога. В исследование включались пациенты в возрастном диапазоне 35-45-ти лет, обоего пола, со стажем заболевания сахарным диабетом 2-го типа, от 5,0 до 6,0 лет с момента документально диагностированного подтверждения, с показателем глюкозы в крови 8,5-9,1 ммоль/л.

Диагностика заболевания тканей пародонта у больных проведена в соответствии с МКБ-10. Больным были проведены обследования с использованием клинических дополнительных и лабораторных методов.

При клиническом обследовании оценивали пародонтальные индексы:

- индексы ПМА, Грина-Вермильона;

- наличие и глубину пародонтальных карманов (с помощью градуированного пародонтального зонда);

- папиллярный индекс кровоточивости PBI.

Дополнительные методы подразумевали оценку панорамной и прицельной рентгенографии, проводили интраоральное исследование цвета десны RGB по Ишихару. Лабораторные методы - биохимические показатели крови, с конкретизацией показателей глюкозы в крови.

Клинические и лабораторные исследования проводили в двух группах больных - основной и группе сравнения, каждая из которых состояла по 23 пациента с выше указанными диагнозами. Все пациенты были разделены на две равноценные группы с помощью таблицы случайных чисел.

Анамнестические данные в подгруппах были идентичными: на чувство болезненности и кро- воточивость десен, выраженную отечность десен, неприятный запах изо рта, на выраженную болезненность десен, особенно при чистке зубов и приеме пищи.

Объективные данные обеих групп до лечения были сопоставимы и реальных отличий не имели. Слизистая десен была гиперемирована, пастозна, десневой край отечен и отставал от зубов, глубина пародонтальных карманов варьировала от 5,9 до 6 мм, что также указывало на степень тяжести заболевания, индекс кровоточивости показывал в основной 49,3\% и группе сравнения 48,1\%, индекс ПМА варьировал от 1,73 до 1,78 , а показатель и Грина-Вермильона составил от 2,70 до 2,72. Проведенные интраоральные исследования с фиксацией цвета десны по шкале RGB по Ишихару наглядно продемонстрировали в сегменте R (красный) следующие показатели от 51,82 до 52,07.

В основной группе в качестве лечения пациенты получали только местную стандартизированную аппликационную терапию на ткани пародонта в амбулаторно-поликлинических условиях, которая заключалась в применении ксимедоновой пасты (ксимедон - 5 мг, токоферола ацетат $30 \%$ розеин - 5,0 мг, хиноксидин - 0,2 г, белая глина q.s. до пастообразной консистенции) в течение 10 дней, а также был назначен препарат плацебо в таблетированной форме для исключения психогенного воздействия.

В группе сравнения, помимо предусмотренных медико-технологических стандартов по лечению генерализованного пародонтита, применялись аппликации в состав которых входил «Мексидол ${ }^{\circledR}$ », в течение 3-5 минут на каждую челюсть, с целью достижения антиоксидантных, антигипоксантных и мембранопротекторных свойств тканей пародонта.

Помимо местного лечения тканей пародонта, пациентам группы сравнения по согласованию с врачом-эндокринологом был назначен в комплексном лечении таблетированный препарат «Мексидол ${ }^{\circledR}$ форте 250» в терапевтических дозах, который больные принимали в течение 10 дней. «Мексидол ${ }^{\circledR}$ форте 250» по своим фармакологическим свойствам способен улучшать микроциркуляцию на тканевом уровне, нормализует клеточный метаболизм, стабилизирует мембраны клеток. Все пациенты были проинформированы о предполагаемом плане лечения и дали информированное согласие на реализацию предложенного плана.

Статистический анализ результатов исследования проведен с использованием программ Biostat, «Statistica 6.0 for Windows» фирмы «StatSoft, Inc.». Для выявления статистически значимых различий средних величин в парных 
сравнениях использовался t-критерий Стьюдента, если распределение изучаемых параметров не соответствовало нормальному (Гауссовому распределению), применялся непараметрический метод и сравнение велось по критерию Вилкоксона-Манна-Уитни. Корреляционный анализ проводился с использованием коэффициента корреляции Пирсона. При малом числе наблюдений, когда общая статистическая совокупность дробилась на группы, достоверность результатов рассчитывалась с использованием одностороннего варианта точного критерия Фишера *. Различия признавались значимыми при $\mathrm{P}<0,05$.

\section{РЕЗУЛЬТАТЫ И ОБСУЖДЕНИЕ}

Перед началом лечения всем пациентам проведена санация и избирательная пришли- фовка зубов в соответствии с окклюзиограммой, проведена профессиональная гигиена полости рта, были удалены ортопедические конструкции, которые не соответствовали медикотехнологическим стандартам с целью устранения провокационных факторов.

В результате проведенного лечения, которое проводилось в течение 10 дней в амбулаторнополиклинических условиях в обеих группах, улучшилось самочувствие больных, снизились стоматологические индексы.

В основной группе через месяц после начала традиционного лечения у пациентов наблюдали незначительное улучшение. Индексы объективно изменились по среднему арифметиче-

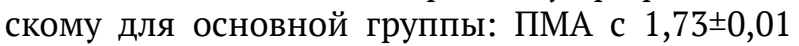

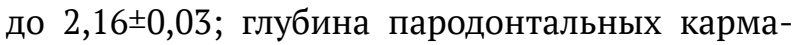

Динамика изменений индексных показателей тканей пародонта

Таблица.

\begin{tabular}{|c|c|c|c|}
\hline Клинический индекс & $\begin{array}{l}\text { День/ } \\
\text { Баллы } \\
\end{array}$ & $\begin{array}{c}\text { Группа сравнения, } \\
\mathrm{n}=23\end{array}$ & $\begin{array}{c}\text { Основная, } \\
n=23\end{array}$ \\
\hline \multirow{4}{*}{$\begin{array}{c}\text { Глубина } \\
\text { пародонтального } \\
\text { кармана }\end{array}$} & 0 & $5,9 \pm 0,17$ & $6,0 \pm 0,15$ \\
\hline & 14 & $5,4 \pm 0,16$ & $5,94 \pm 0,14$ \\
\hline & 30 & $5,1 \pm 0,16$ & $5,65 \pm 0,12$ \\
\hline & \multicolumn{2}{|c|}{$\mathrm{P}<0,01$} & $\mathrm{P}<0,01$ \\
\hline \multirow{4}{*}{ ПМА } & 0 & $1,78 \pm 0,09$ & $1,73 \pm 0,01$ \\
\hline & 14 & $0,99 \pm 0,07$ & $1,43 \pm 0,05$ \\
\hline & 30 & $0,32 \pm 0,05$ & $1,01 \pm 0,09$ \\
\hline & \multicolumn{2}{|c|}{$\mathrm{P}<0,003$} & $\mathrm{P}<0,003$ \\
\hline \multirow{4}{*}{ Грина-Вермильона } & 0 & $2,70+0,02$ & $2,72 \pm 0,02$ \\
\hline & 14 & $1,96 \pm 0,02$ & $1,87 \pm 0,07$ \\
\hline & 30 & $0,98+0,05$ & $1,06 \pm 0,04$ \\
\hline & \multicolumn{2}{|c|}{$\mathrm{P}<0,03$} & $\mathrm{P}<0,03$ \\
\hline \multirow{6}{*}{$\begin{array}{c}\text { Индекс } \\
\text { кровоточивости РВI } \\
\text { в баллах } \\
\text { 0-14-30 день }\end{array}$} & 0 & $-/-/ 8,5$ & $-/-/ 9,8$ \\
\hline & 1 & $-/ 3,4 / 23,4$ & $-/ 0,9 / 17,9$ \\
\hline & 2 & $2,6 / 6,8 / 33,8$ & $1,9 / 4,2 / 34,8$ \\
\hline & 3 & $48,1 / 43,4 / 18,1$ & $50,0 / 49,2 / 22,5$ \\
\hline & 4 & $49,3 / 46,4 / 14,9$ & $48,1 / 45,7 / 21,6$ \\
\hline & \multicolumn{2}{|c|}{$\mathrm{P}<0,04$} & $\mathrm{P}<0,04$ \\
\hline \multirow{4}{*}{$\begin{array}{c}\text { Интраоральное исследование } \\
\text { цвета десны RGB по Ишихару } \\
\text { (\%) }\end{array}$} & 0 & $52,07 \pm 0,04$ & $51,82 \pm 0,05$ \\
\hline & 14 & $36,01 \pm 0,03$ & $42,27 \pm 0,05$ \\
\hline & 30 & $25,05 \pm 0,06$ & $30,08 \pm 0,07$ \\
\hline & \multicolumn{2}{|c|}{$\mathrm{P}<0,02$} & $\mathrm{P}<0,02$ \\
\hline
\end{tabular}

Примечание: * - корреляционный анализ Пирсона и односторонний вариант точного критерия Фишера использовались при расчете многокомпонентных критериев ПМА и при анализе интраоральных исследований цвета десны RGB по Ишихару; Р относятся к достоверной разнице относительно групп сравнения в период 0-30 дней. 
нов с $6,0 \pm 0,15$ до $5,65 \pm 0,12$; Грина-Вермильона с $2,72 \pm 0,02$ до $1,06 \pm 0,04$, индекс кровоточивости PBI от 50,0 до 22,5, а интраоральное исследование цвета десны RGB по Ишихару с 51,82 $\pm 0,05$ до 30,08 $\pm 0,07$ (см. табл.).

После проведенного лечения в основной группе первые признаки рецидивирования начали провялятся через четыре месяца, при этом показатель сахара у больных был стабильным 7,0 - 7,2 ммоль/л.

В группе сравнения, где применялись аппликации на слизистую оболочку полости рта в состав которых входил «Мексидол ${ }^{\circledR}$ » в течение 3-5 минут на каждую челюсть и использование таблетированного «Мексидол ${ }^{\circledR}$ форте 250 » в терапевтических дозах, которые больные принимали в течении 10 дней, у пациентов наблюдали улучшение стоматологического статуса, положительную динамику использованных индексов.

В группе сравнения через месяц после начала лечения у пациентов индексы объективно изменились по среднему арифметическому для группы сравнения: ПМА с 1,73 $\pm 0,01$ до $0,32 \pm 0,05$; глубина пародонтальных карманов с $5,9 \pm 0,17$ до 5,1 $\pm 0,16$; индекс кровоточивости РВI изменялся по всем баллам и балансировал от 9,8 до 14,9, индекс Грина-Вермильона с 2,70+0,02 до $0,98+0,05$, а компьютерный анализ исследования цвета десны RGB по Ишихару в показателе R

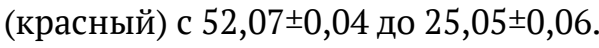

В группе сравнения после проведенного комплексного лечения, первые признаки рецидивирования проявились через семь месяцев, показатель глюкозы балансировал от 6,9 до 7,1 ммоль/л.

\section{З АК ЛЮЧЕНИЕ}

Фармакологические свойства аппликаций, в состав которых входит «Мексидол ${ }^{\circledR}$ » обосновывают его способность воздействовать на разные патогенетические звенья пародонтита. Установлено, что внутриоральные аппликации на слизистую оболочку альвеолярной кости позитивно влияют на различные факторы (гипоксию, воспаление, интоксикацию). Внутриоральные аппликации гармонично сочетается с различными лекарственными средствами, в частности «Мексидол ${ }^{\circledR}$ форте 250» в терапевтических дозах, что повышает резистентность организма, нормализует метаболизм клеток, усиливает аэробный гликолиз, улучшает усвоение кислорода. Предложенный комплексный подход повышает устойчивость организма к кислородозависимым патологическим процессам, что в последствии способствует к более прогрессивному устранению признаков воспаления и увеличению сроков ремиссии при генерализованных формах пародонтита I-II степени тяжести с учетом фоновых заболеваний.

\section{И.В. Бугорков, Е.В. Бухтиярова, И.А. Бугоркова}

ГОО ВПО «Донецкий национальный медицинский университет имени М. Горького», Донецк

\section{ОЦЕНКА ЭФФЕКТИВНОСТИ ПРИМЕНЕНИЯ ПРЕПАРАТА «МЕКСИДОЛ» В КОМПЛЕКСНОМ ЛЕЧЕНИИ БОЛЬНЫХ ГЕНЕРАЛИЗОВАННЫМИ ЗАБОЛЕВАНИЯМИ ТКАНЕЙ ПАРОДОНТА}

Сахарный диабет наиболее часто проявляется у лиц с генетической предрасположенностью и людей старших возрастных групп, у которых инсулин в организме вырабатывается в недостаточном количестве, а это приводит к полиорганным изменениям. На фоне сахарного диабета, происходит изменение индексных показателей тканей пародонта, которые приводят к нарушениям энергетических процессов в эпителиальных клетках, к изменениям метаболизма и нарушением на клеточном уровне их барьерной функции. За счет эндокринных нарушений, заболевания тканей пародонта проявляются наиболее агрессивно по течению и тяжести, приводят к тканевой гипоксии, и в последствие приводят к развитию хронического воспалительно-деструктивного процесса. Использование антиоксидантных препаратов способствуют стабилизации окислительно-востановительных процессов на тканевом и клеточном уровне, за счет выраженных мембранопротекторных свойств. В результате проведенных исследований нами были определены рекомендации применения препарата «Мексидол ${ }^{\circledR}$ и Мексидол ${ }^{\circledR}$ форте 250 » в комплексном лечении больных с генерализованным пародонтитом на фоне сахарного диабета.

Ключевые слова: мексидол, генерализованный пародонтит, противовоспалительный и регенерирующий эффект, сахарный диабет. 


\section{I.V. Bugorkov, E.V. Bukhtiyarova, I.A. Bugorkova}

\section{SEI HPE «M. Gorky Donetsk National Medical University», Donetsk}

\section{ESTIMATION OF EFFICIENCY OF APPLICATION OF THE PRODUCT “MEXIDOL" IN THE COMPLEX TREATMENT OF PATIENTS WITH GENERALIZED DISEASES OF PERIODONTAL TISSUES}

Diabetes mellitus is most often manifested in people with a genetic predisposition and people of older age groups, in which the insulin in the body is not produced in sufficient quantities, and this leads to multiple organ changes. Against the background of diabetes mellitus, there is a change in the index indicators of periodontal tissues, which lead to disturbances in the energy processes in epithelial cells, to changes in metabolism and a violation at the cellular level of their barrier function. Due to endocrine disorders, periodontal tissue diseases manifest themselves most aggressively with the course and sever- ity, lead to tissue hypoxia, and subsequently lead to the development of a chronic inflammatory and destructive process. The use of antioxidant drugs helps to stabilize redox processes at the tissue and cellular levels, due to pronounced membrane-protective properties. As a result of our studies, we determined the recommendations for the use of the drug “Mexidol ${ }^{\circledR}$ and Mexidol ${ }^{\circledR}$ forte 250 ” in the complex treatment of patients with generalized periodontitis against diabetes mellitus.

Key words: mexidol, generalized periodontitis, antiinflammatory and regenerative effect, diabetes mellitus.

\section{ЛИТЕРАТУРА}

1. Сунцов Ю.А., Болотская Л.Л., Маслова О.В., Казаков И.В. Эпидемиология сахарного диабета и прогноз его распространенности. Сахарный диабет. 2011; 1: 15-18.

2. Антонова К.В., Недосугова Л.В., Балаболкин М.И. Влияние компенсации углеводного обмена на свободнорадикальное окисление липопротеинов низкой плотности и активности ферментов антиоксидантной системы при сахарном диабете типа 2. Бюл. ЭКПЕРИМ. БИОЛ. И МЕД. 2003; Т. 49, 2: 51-53.

3. Kerstens M.N., Riemens S.C., Sluiter W.J. [et al.] Lack of relationship between $11 \beta$-hydroxysterolid dehydrogenase setpoint and insulin sensitivity in the basal state and after $24 \mathrm{~h}$ of insulin infusion in healthy subjects and type 2 diabetic patients. Clin. Endocrinol. (Oxf). 2000; 4 (52): 403-411.

4. Древаль А.В., Мисникова И.В., Барсуков И.А., Тишенина Р.С. Возможности профилактики сахарного диабета 2 типа у лиц с ранними нарушениями углеводного обмена. Проблемы эндокринологии. 2008; 5: 3-7.

5. Eisenbarth G. Type 1 diabetes mellitus. A chronic autoimmune disease. N Engl. J. Med. 1986; 314 (21): 1360-1368.

6. Файзулина Д.Б., Мингазов Г.Г. Состояние тканей пародонта у больных сахарным диабетом. Медицинский вестник Башкортостана. 2009; Т. 4, 5: 69-74.

7. Бабіна О.О. Клініко-патогенетичні аспекти захворювань тканини пародонту у дітей із цукровим діабетом. Укр. мед.стомат. академія. 2001; Т. 46, 6: 29-34.

8 Танченко О.А., Нарышкина С.В. Особенности лечения сахарного диабета 2 типа/ Здоровье и образование в XXI веке. 2012; 3, Т. 14: 167

9. Скрипников П.Н., Суковач О.Г. Особенности микробиоценоза слизистой оболочки полости рта у больных сахарным диабетом 2 типа и атеросклерозом, его коррекция антиоксидантами. Вісник проблем біології i медицини. 2007; 3: 134-137.

\section{REFERENCES}

1. Suntsov Yu.A., Bolotskaya L.L., Maslova O.V., Kazakov I.V. Epidemiologiya sakharnogo diabeta i prognoz ego rasprostranennosti. Sakharnyi diabet. 2011; 1: 15-18 (in Russian).

2. Antonova K.V., Nedosugova L.V., Balabolkin M.I. Vliyanie kompensatsiiuglevodnogoobmenanasvobodnoradikal'noe okislenie lipoproteinov nizkoi plotnosti i aktivnosti fermentov antioksidantnoi sistemy pri sakharnom diabete tipa 2. Byul. EKPERIM. BIOL. I MED. 2003; T. 49, 2: 51-53 (in Russian).

3. Kerstens M.N., Riemens S.C., Sluiter W.J. [et al.] Lack of relationship between $11 \beta$-hydroxysterolid dehydrogenase setpoint and insulin sensitivity in the basal state and after $24 \mathrm{~h}$ of insulin infusion in healthy subjects and type 2 diabetic patients. Clin. Endocrinol. (Oxf). 2000; 4 (52): 403-411.

4. Dreval' A.V., Misnikova I.V., Barsukov I.A., Tishenina R.S. Vozmozhnosti profilaktiki sakharnogo diabeta 2 tipa u lits s rannimi narusheniyami uglevodnogo obmena. Problemy endokrinologii. 2008; 5: 3-7 (in Russian).

5. Eisenbarth G. Type 1 diabetes mellitus. A chronic autoimmune disease. N Engl. J. Med. 1986; 314 (21): 1360-1368.

6. Faizulina D.B., Mingazov G.G. Sostoyanie tkanei parodonta $\mathrm{u}$ bol'nykh sakharnym diabetom. Meditsinskii vestnik Bashkortostana. 2009; T. 4, 5: 69-74 (in Russian).

7. Babina O.O. Kliniko-patogenetichni aspekti zakhvoryuvan' tkanini parodontu u ditei iz tsukrovim diabetom. Ukr. med. stomat. akademiya. 2001; T. 46, 6: 29-34 (in Russian).

8 Tanchenko O.A., Naryshkina S.V. Osobennosti lecheniya sakharnogo diabeta 2 tipa/Zdorov'e i obrazovanie v KhKhI veke. 2012; 3, T. 14: 167 (in Russian).

9. Skripnikov P.N., Sukovach O.G. Osobennosti mikrobiotsenoza slizistoi obolochki polosti rta u bol'nykh sakharnym diabetom 2 tipa i aterosklerozom, ego korrektsiya antioksidantami. Visnik problem biologiï i meditsini. 2007; 3: 134-137 (in Russian). 